\title{
Applying valence framing to enhance the effect of information on transport-related carbon dioxide emissions
}

Paper accepted to a special issue of Transportation Research Part A (Psychology of Sustainable Mobility)

\author{
Erel Avineri ${ }^{1}$ and E. Owen Waygood
}

Centre for Transport \& Society, Faculty of Environment and Technology, University of the West of England, Coldharbour Lane, Bristol UK BS16 1QY

\begin{abstract}
The provision of information on transport-related carbon dioxide $\left(\mathrm{CO}_{2}\right)$ to the traveller can be seen as an instrument to increase the likelihood of more sustainable choices being made by individuals. However, as transport-related $\mathrm{CO}_{2}$ emissions are largely seen as a 'social' cost rather than a 'private' cost to the individual, the behavioural engagement with and response to information on environmental effects of travel choices may therefore be limited. It is argued that framing, studied in a range of contexts, can be used to enhance the evaluation of choice attributes and promote desirable (more sustainable) choices. An experiment is reported that examine the effect of valence framing of amounts of $\mathrm{CO}_{2}$ emissions on the perceived differences between alternative travel modes. Through the use of positive and negative terms, the information was framed to focus attention either on the potential of a travel mode to provide environmental benefit (positive frame) or on its potential to reduce an environmental loss (negative frame). Survey participants' estimates of $\mathrm{CO}_{2}$ amounts were compared for positive and negative framing of the same information using an ordered logit (OL) model. The findings imply that negative framing is more effective than positive framing in highlighting differences between $\mathrm{CO}_{2}$ amounts of alternative travel modes and therefore is more likely to influence travel-related choices.
\end{abstract}

\section{Keywords}

Carbon dioxide emissions, valence framing, travel information

\footnotetext{
${ }^{1}$ Corresponding author. Tel: +44 1173283197 . Fax: +44 1173283002.

E-mail addresses: Erel.Avineri@uwe.ac.uk, Owen.Waygood@uwe.ac.uk
} 


\section{Introduction}

Growing concerns over climate change and environmental issues are leading governments and citizen groups to take action to change the way people travel. Providing individuals with information about transport-related attributes such as travel time, costs or environmental impacts may be seen not only as a service provided to the public, but as an instrument to change travel behaviour. The common presumption is that informed travellers will make better choices which will be to their personal advantage as well as potentially that of the transport system and the environment.

Goal framing implies that information are framed as making oneself feel better now, protect or improve one's resources, or to act appropriately (Lindenberg \& Steg, 2007). The effects of climate change have external costs rather than personal losses to the traveller and therefore sustainable mobility choices as a contributor to climate change could be seen as a social dilemma (e.g. Milinski et al., 2008; Whitmarsh, 2009), and would thus relate to the framing of "acting appropriately". The provision of information on greenhouse gases (GHG) emissions generated by transport can be seen as an instrument to increase the likelihood of acting appropriately, also termed a normative goal. While there is little empirical evidence on the effect of such information, it is widely accepted that without providing information on GHGs such as carbon dioxide $\left(\mathrm{CO}_{2}\right)$ it is less likely that individuals will make climate-friendly travel choices. At the level of the individual traveller, their environmental behaviour (i.e. acting appropriately) will be governed in part by how they perceive the differences between how much $\mathrm{CO}_{2}$ emissions are associated with alternative travel choices.

A general lack of experience and knowledge of climate change information may affect people's ability to judge differences in $\mathrm{CO}_{2}$ emissions. $\mathrm{CO}_{2}$ emissions are a relatively new concept and the levels of individual GHG emissions to meet environmental goals are largely unknown to many (Coulter et al., 2007; Waygood and Avineri, 2011). Therefore, it would be difficult for people to perceive a difference between two amounts associated with travel alternatives.

It can generally be argued that the design of travel information has often ignored the psychological environment of travel choice. While rational choice theory suggests that individuals base choices on the attributes of the choice set (information content), the way information is being presented (information context) can also have a strong effect on travellers' use of and reaction to information. This is the focus of the present study. However, little research has been done on the effectiveness of the design of travel information context. Following research in cognitive psychology we explore how the concept of valence framing may be applied to enhance the perception of differences between $\mathrm{CO}_{2}$ emission amounts. Through the use of positive and negative terms, such information can be framed to focus attention either on the potential of a travel mode to provide environmental benefit (positive frame) or on its potential to reduce an environmental loss (negative frame). The effect of valence framing on the perceived difference between amounts of $\mathrm{CO}_{2}$ emissions is studied through an experiment administered as a survey. In 
the survey one negative and one positive framed question were asked. An ordered logit model was used to examine whether there were statistically significant differences in the ordinal responses to the question varying from about the same, slightly different, and much different amounts of $\mathrm{CO}_{2}$ emissions.

The present article has six sections. Section 2 provides a brief discussion regarding the two above-mentioned paradigms, namely information content and information context, the effect of information content and information context on the evaluation of travel choices, and how these paradigms stemmed from thinking in neoclassical economics and psychology. It is followed by section 3 which reviews the literature on two distinct types of framing: valence framing and goal framing. Section 4 presents the research methodology and the design of the survey experiment to test the effect of negative vs. positive framing of information about $\mathrm{CO}_{2}$ emissions. The results and analysis of the survey responses are provided in section 5 . The potential to apply valence framing to influence transport choices is discussed in section 6 . Conclusions and some further research and implementation are also presented in this section.

\section{Providing travellers with information on $\mathrm{CO}_{2}$ emissions: Two paradigms}

It can be argued that the main thinking in transport planning and policy making stem from neoclassical economics in which travellers are assumed to make choices which are rational, consistent, and efficient, and apply cognitive processes to maximise their economic utility (Avineri, 2012). For example, Ben-Akiva and Lerman (1985) describe the theory of choice as a collection of procedures that are defined by the following elements: (i) decision maker, (ii) alternatives, (iii) attributes of alternatives, and (iv) a decision rule. The attractiveness of an alternative in the mind of the decision maker (the individual traveller) is described as a utility that is a function of the attribute values.

Travel choices can relate to many utility components associated with the attributes of alternatives: travel time, travel cost (real or perceived), comfort, convenience, safety, and others. Those attributes are mostly associated with the hedonic ("feeling better right now") or gain goals ("protecting or improving one's resources"). With high awareness about and shifting attitudes towards climate change (Eurobarometer, 2009), normative goal-related information such as carbon emissions generated by transport might also be important to individual travellers when making choices (such as selecting a mode of travel for a journey, or purchasing a new vehicle, e.g. Gaker et al., 2011).

According to rational choice theory, providing information about what people value (whether hedonic, gain, or normative goals) may help swing the pros and cons of the decisional balance. For example, providing normative goal information on the amounts of carbon emissions generated by alternative travel choices may influence the choices of individuals and increase the likelihood of sustainable choices to be made by them (e.g. Gaker et al., 2010). 
In some programmes and initiatives, information on $\mathrm{CO}_{2}$ emissions is being given to individual travellers in the hope that it will raise awareness on travelrelated emissions and help them make informed (and more sustainable) travel decisions. A range of web-based tools provide transport-related $\mathrm{CO}_{2}$ information to individual travellers; these include carbon dioxide calculators and journey planners - such as, for example, the UK national journey planner Transport Direct (www.transportdirect.info). $\mathrm{CO}_{2}$ information is also provided to participants of travel programs such as Travel Blending in Australia (Rose and Ampt, 2001) and Travel Feedback Program in Japan (Taniguchi et al., 2003). Despite the increasing presence of $\mathrm{CO}_{2}$ information, there seems to be little research on whether people understand or how they perceive this information. Coulter et al. (2007) found that both users and non-users of carbon dioxide calculator websites reported not really understanding the results when presented in units of mass. The interpretation of information likely depends on the users' background knowledge and the provided context.

If individuals are expected to act rationally, and specifically to exhibit consistency and transitivity in their choices. How alternatives and attributes are presented to the traveller should not matter, and individuals should not be affected by irrelevant context (Avineri, 2012). However, neoclassical economics and psychology have different views of choice making. Extensive research since Simon (1956) critized economic theories of rational behaviour has come to question these theories validity (e.g., XXX). Simon argued that the behaviour of an individual should be understood relative to the constraints of the environment, and that "no utility function needs to be postulated for the organism, nor does it require any elaborate procedure for calculating marginal rates of substitution among different wants" (p. 273).

\section{Framing effects}

\subsection{Valence framing}

The theory of rational choice assumes that no matter how information is presented or framed, an individual will always have the same interpretation of the information. Thus, preferences should not be affected by framing. But the format in which information is presented may affect how it is been processed by the individual, referred to by McFadden as a category of cognitive anomalies called context effects.. Over the past two decades, studies of so-called framing effects in a range of contexts have explored how individuals respond differently to equivalent descriptions of the same decision alternatives presented in different formats.

Framing is here defined as a semantic restructuring of identical problems (Hallahan, 1999). What is referred to semantic framing may reorganize a sentence so that a key point comes in the beginning rather than at the end. Valence framing attempts to put the same information in either a positive or a negative light. In a transport decision process, a scheme or policy may be described as "reducing $\mathrm{CO}_{2}$ emissions by $10 \%$ " which highlights the positive impact of the scheme in relation to the current situation. Through the use of positive and negative terms, the same critical information can be framed to focus attention either on its positive or negative aspects. For $\mathrm{CO}_{2}$ emissions information it is important to know which framing will better highlight 
differences between choices so that the potential of a person to select the more environmentally benign one might increase.

People treat positive impacts, or gains, and negative impacts, or losses, differently. This observed behaviour is called loss aversion (or loss-gain asymmetry) and refers to that people tend to be more sensitive to losses than gains (Kahneman and Tversky, 1979). Across many contexts, the impact of negatively framed information has consistently been found to be stronger than the impact of the same information framed in positive terms of the same magnitude. The so-called loss framing refers to semantically restructuring (framing) a choice so that the tendency for people to avoid losses (loss aversion) guides them to a particular choice. Tversky and Kahneman (1991) summarized findings that the coefficient of loss framing (the relative strength of effects of gain framing to loss framing) was greatest for personal safety, followed by money, and then leisure.

The effectiveness of valence framing in the context of travel information is not known. However, several recent studies have explored loss aversion associated with travel choices. The emerging evidence indicates that travellers provided with information on travel times of alternative travel options exhibit aversion to loss and have a strong tendency to avoid choices associated with losses (see, e.g., Avineri and Prashker, 2004; van de Kaa, 2010; Rose and Masiero, 2010). Avineri (2006) demonstrated how changes in the perceived value of the reference point in a route-choice problem could lead to improved traffic equilibrium.

\subsection{Goal framing}

Levin et al. (1998) argue that the so-called valence framing effects are often treated as a relatively homogenous set of phenomena explained by a single theory, prospect theory (Kahneman and Tversky, 1979). Following a critical analysis of the evidence on framing effects, Levin et al. suggested a typology of valence framing effects. They classified previous valence framing research to three categories: (i) risky choice framing, in which the options differ in risk level (in line with the conceptual framework of prospect theory); (ii) attribute framing, in which a single attribute of an object is framed; and (iii) goal framing, in which the consequences of behaviour are specified.

Goal framing pertains to enhancing the evaluation of a behaviour (Levin et al., 1998). It applies to the context of $\mathrm{CO}_{2}$ emissions. As alreadynoted, goal framing can be further posit to apply to hedonic, gain, and normative goals (Lindenberg and Steg, 2007). Hedonic goals aim to improve how one feels at the time. Gain goals aim to protect or improve upon one's resources (e.g. time, money). Normative goals relate to what ought to be done (e.g. for society's or the environment's benefit). According to Lindenberg and Steg, normative goals are most strongly associated with environmental behaviour. Goal framing relates to the type of information being considered, which differs from valence framing's application to how information is presented.

\subsection{Applying valence framing}


Both positive and negative frames should enhance the evaluation of the object, by nudging towards a relatively attractive choice, or by making an inferior choice less attractive. Although both frames can be seen as enhancers of the evaluation process, a negatively framed message emphasizing losses tends to have a greater impact on a targeted behaviour than a comparable positively framed message emphasizing gains. For example, Meyerowitz and Chaiken (1987) studied the effect of information on breast self-examination (BSE). Messages such as:

"Research shows that women who do not do BSE have a decreased chance of finding a tumour in the early, more treatable stages of the disease"

were included in a loss-framed pamphlet, while a gain-framed pamphlet used messages such as:

"Research shows that women who do BSE have an increased chance of finding a tumour in the early, more treatable stages of the disease".

It was found that the loss frame pamphlet led women to stronger BSE attitudes, intentions and behaviours more than the gain frame pamphlet.

Levin et al. (1998) found that for goal framing, loss framing usually had a greater effect. Studies from specific fields such as health (Kühberger, 1998) and home energy use (Gonzales et al, 1988) have also found that framing affects choice. For the health field a meta-analysis of 136 empirical papers found that loss framing is a reliable phenomenon (Kühberger, 1998). However, both those fields deal with losses to the individual, so would be termed gain-goal framing within the goal framing categorisation. Further they deal with topics that are relatively familiar to most individuals such as financial loss or negative health impacts. Therefore, there remains a gap in knowledge about whether valence framing techniques such as loss framing would have the same effect on normative goal framing.

As a result of valence framing's success in influencing choices in other fields, the need for an investigation on $\mathrm{CO}_{2}$ emissions may seem limited. However, most research into valence framing did not consider social dilemmas such as climate change, and the nature of impacts of framing might be different in such situations. In the context of transport, the problem of climate change can be considered a social dilemma as people might feel that their personal mobility is being restricted, while the benefits of those restrictions accrue to the global society as a whole. Information related to such impacts relate to normative goals. In contrast, considerations of personal health or finance have a direct impact on the individual and are gain goals so the desire to avoid risk may be greater than if one's actions do not have a direct personal impact, such as the case of $\mathrm{CO}_{2}$ impacts.

Additionally, most of the studies of valence framing effects reported in the literature deal with situations in which information is directly relevant and familiar to the individual. However, for the common traveller, $\mathrm{CO}_{2}$ information is a relatively new issue; many travellers have little direct experience with its measurement and effect, and difficulty in interpreting it (Coulter et al., 2007; Waygood and Avineri, 2011). It is therefore not obvious that valence framing 
techniques successfully applied in other fields will be effective in a climate change context.

\subsection{Valence framing within goal framing}

To summarize, the evidence on $\mathrm{CO}_{2}$ information being presented to individuals suggest that it does affect decisions (e.g. Gaker et al., 2010), but the magnitude of its impact could potentially be increased through contextual design of the information, such as applying valence framing. However, there are a number of differences between $\mathrm{CO}_{2}$ information and previous applications of negative framing that may influence its effectiveness such as familiarity and indirect impact. Further, information about $\mathrm{CO}_{2}$ emissions can be seen as a normative goal framing, whereas previous studies on valence framing mostly focus on gain-goal framing. Therefore, research that examines whether positive or negative goal framing could affect the perceived difference between the amounts of $\mathrm{CO}_{2}$ emissions by different modes may contribute to the building of more effective communication tools.

There is a potential that valence framing could affect perceptions of $\mathrm{CO}_{2}$ emissions as it might stimulate positive or negative associations of the environmental effects of alternative travel modes. The next section will introduce our method for investigating the effect of valence framing on the perception of $\mathrm{CO}_{2}$ emissions associated with travel alternatives.

\section{Method}

Information by itself is likely insufficient to substantially change travel behaviour. However, it can generally be argued that in combination with other soft and hard policy measures it can support behaviour change. In the cognitive model for decision making, an individual's perceptions of choice attributes, her attitudes toward a behaviour, and a set of beliefs associated with it (such as social norms) all have roles in affecting choice. In the design and implementation of behaviour change interventions, the targeted behaviour can be addressed by a set of measures that highlight the different determinants of behaviour relevant in the context, ideally ensuring they are all pulling in the same direction. Individual choice to travel in a more sustainable way is a rather complex issue; the individual traveller's set of utilities, attitudes and beliefs regarding their transport options, as well as emotive content and habits are important determinants of travel behaviour however they are not the focus of this study which aims to explore the effect of framing on the perception of $\mathrm{CO}_{2}$ emissions evaluated by an individual traveller. A direct measure is employed by asking participants to indicate the amount of $\mathrm{CO}_{2}$ emissions by travel mode.

An experiment administered as a survey was launched to examine whether positive or negative goal framing is more powerful in enhancing the perception of differences between the $\mathrm{CO}_{2}$ emissions of alternative travel modes, presented in grams per 5-mile journey (the combination of metric and imperial units is a quirk of common use in the UK). To test the effectiveness of positive and negative goal framing, two comparison sets were semantically restructured so that environmental gains and losses were distinctly presented. 
As the literature report that negative framing of goals is generally more effective than positive framing to influence choice (Levin et al., 1998), the anticipated result is that negative framing will have a greater impact on how $\mathrm{CO}_{2}$ amounts are perceived. In order to eliminate the impact of other considerations on choice (such as comfort, cost, etc.) this experiment only considers the perception of the difference between two $\mathrm{CO}_{2}$ amounts. Thus, we hypothesize that negative goal framing will result in a greater perceived difference between the $\mathrm{CO}_{2}$ amounts than positive goal framing.

The comparison sets were based on the per passenger amounts of $\mathrm{CO}_{2}$ emissions produced over a five mile trip by a bicycle, car occupied with four passengers, and single occupancy $4 \times 4$ (or sports utility vehicle). The amounts were $132 \mathrm{~g}, 500 \mathrm{~g}$, and $3400 \mathrm{~g}$ respectively and were calculated using www.travelfootprint.org. The resulting comparison sets were $132 \mathrm{~g}$ versus $500 \mathrm{~g}$, and $500 \mathrm{~g}$ versus $3400 \mathrm{~g}$. After semantically reorganizing the comparison sets in the four sentences shown in Figure 1.

Set $1(132 \mathrm{~g}$ against $500 \mathrm{~g})$

i. $\quad$ Gain framing for comparison set 1:

Mode $X$ produces $500 \mathrm{~g}$ of $\mathrm{CO}_{2}$ for a 5 mile trip.

The amount produced by mode $\mathrm{Y}$ is $368 \mathrm{~g}$ lower (i.e. better).

ii. Loss framing for comparison set 1:

Mode $\mathrm{X}$ produces $132 \mathrm{~g}$ of $\mathrm{CO}_{2}$ for a 5 mile trip.

The amount produced by mode $\mathrm{Y}$ is $368 \mathrm{~g}$ higher (i.e. worse).

Set 2 (500g against $3400 \mathrm{~g})$

iii. Gain framing for comparison set 2:

Mode $X$ produces $3400 \mathrm{~g}$ of $\mathrm{CO}_{2}$ for a 5 mile trip.

The amount produced by mode $\mathrm{Y}$ is $2900 \mathrm{~g}$ lower (i.e. better).

iv. Loss framing for comparison set 2:

Mode $\mathrm{X}$ produces $500 \mathrm{~g}$ of $\mathrm{CO}_{2}$ for a 5 mile trip.

The amount produced by mode $\mathrm{Y}$ is $2900 \mathrm{~g}$ higher (i.e. worse).

Fig. 1. The gain and loss framing for two $\mathrm{CO}_{2}$ emissions comparison sets.

Those four sentences were assigned to survey participants so that each participant was asked to provide a response to one message with gain framing and one with loss framing, but not of the same comparison set (e.g. $i$ and iv, or ii and iii, Figure 1). The order of the gain and loss framing was randomized. To avoid associations of sustainability with actual modes, the alternative modes were not described. For each comparison, the participants were asked "Compared to mode $X$, mode $Y$ is...." The response choices were on an ordinal scale of "about the same," "slightly different," or "much different" amounts. 
The survey sample included 194 adult participants who ranged in age from 19 to 76 (average 39 ) years old, $48.4 \%$ were female, and $57.5 \%$ had higher education. The questions were part of a larger survey that was administered through the Carbon Aware Travel CHoices (CATCH) project (see www.carbonaware.eu).

\section{Results}

The descriptive results of the responses of perceived differences to the two comparison sets are presented in Figure 2. First, for both comparison sets, there is among those participants who responded to a question framed in negative terms an apparent increase in the number perceiving the alternative transport modes to be "much different" by their $\mathrm{CO}_{2}$ emissions. This suggests that negative goal framing increases the perceived difference between $\mathrm{CO}_{2}$ amounts. Second, the responses to the two questions framed in positive terms (i, iii, Figure 1) are extremely similar despite different people completing the questions and comparison sets with different magnitudes of $\mathrm{CO}_{2}$ being compared. Third, the effect of negative goal framing is more pronounced in the second comparison set with larger amounts being compared. Those last two observations suggest that the effect of scale, or magnitude, should be considered in the statistical analysis.

The descriptive results suggest that there may be impacts from both negative goal framing and the scale of the $\mathrm{CO}_{2}$ being compared on how people perceive the difference. In order to test whether these differences were statistically significant, an ordered logit (OL) model was used with the dependent variable being the response on perceived difference. OL models are used to examine ordinal-scale dependent variables (such as "high, medium, low") and therefore are appropriate for this type of analysis (see Ben-Elia \& Ettema, 2009, for a more detailed description of OL models). The models were estimated with the BIOGEME software version 1.6 (Bierlaire, 2003, 2008). To allow for analysis, the responses regarding differences between the $\mathrm{CO}_{2}$ amounts presented to the participants, "about the same", "slightly different", and "much different" were coded as 0,1 , and 2, accordingly. 
a)
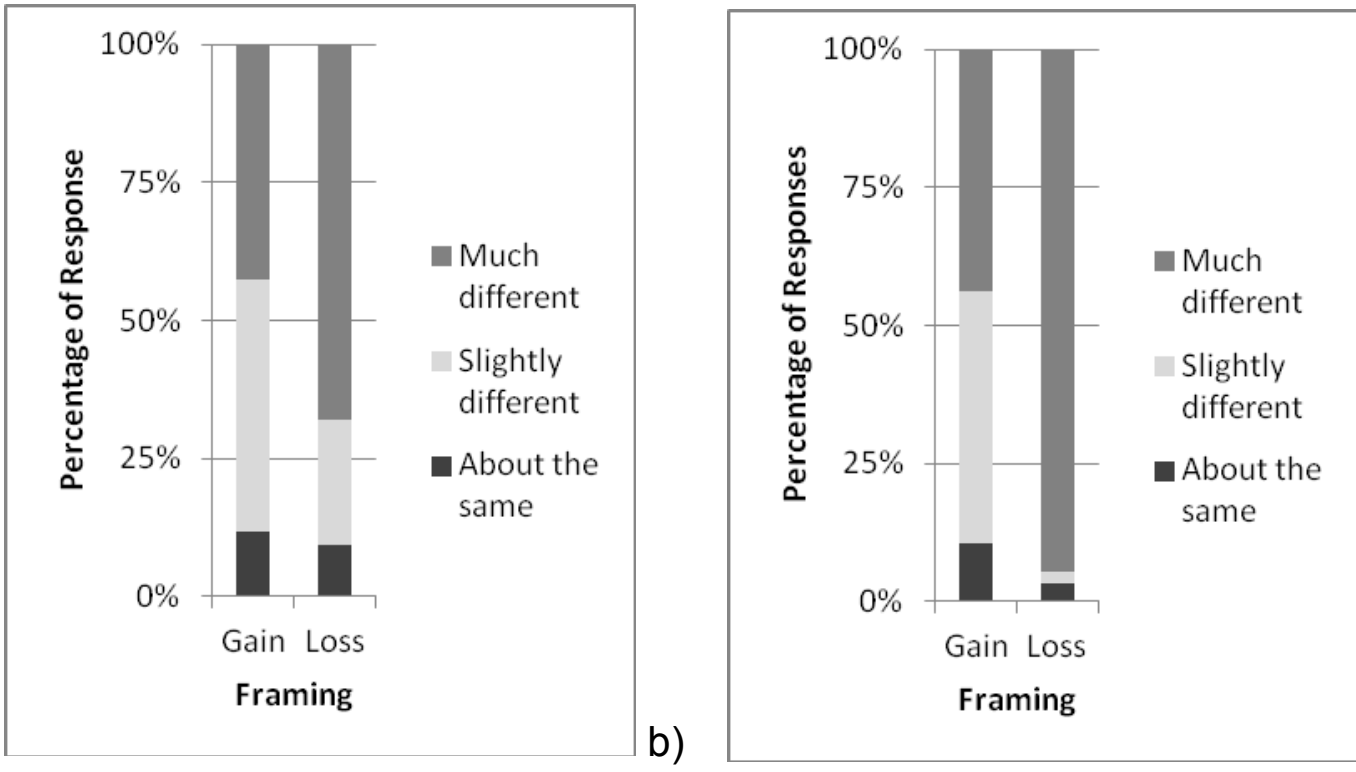

Fig. 2. Generalized response to gain and loss framing for) $132 \mathrm{~g}$ versus $500 \mathrm{~g}$ (left) and $500 \mathrm{~g}$ versus $3400 \mathrm{~g}$ (right).

From the descriptive results, the scale of the comparison ('small' $\mathrm{CO}_{2}$ outputs presented as set 1, or 'large' $\mathrm{CO}_{2}$ outputs presented at set 2, see Figure 2) appeared to be relevant, so a dummy variable was included.

Although the primary focus of this paper is the effect of negative vs. positive goal framing, and although the sample was not intended to be a represetaitive one, including socio-demographic variables in the model may still provide further understanding of the effect of valence framing. For example, Fagley and Miller (1997) showed that in some situations gender may influence framing effects; according to other studies, education has been found to have an effect on the impact of framing, with more impact of framing among participants who had less than a college education (see, e.g., Armstrong et al., 2002). Thus, to check for any impact of gender or education, those variables were also included in an initial model. However, as both gender and education were found to be insignificant $(p=0.49$ and $p=0.82$ respectively), they were removed from the model. The final model results are shown in Table 1. It presents the results of the OL estimation for perception of differences between $\mathrm{CO}_{2}$ amounts of the transport alternatives.

The results shown in Table 1 are that both positive/negative goal framing and scale differences explained a significant amount of the variance, and that framing had the larger overall effect. The parameters were both positive, confirming the interpretation of the descriptive results, that negative goal framing of $\mathrm{CO}_{2}$ amounts and larger $\mathrm{CO}_{2}$ values increase the likelihood of alternative transport options to be perceived as "much different." Using the adjusted rho squared, the model explained nearly $25 \%$ of variance.

Odds ratios can be used to determine the likelihood of the transport modes perceived to be "much different" in comparison with being perceived as either "about the same" or "slightly different." For the comparison between $132 \mathrm{~g}$ and $500 \mathrm{~g} \mathrm{CO}_{2}$ amounts, the odds ratio that the difference will be interpreted as "much" for negative goal framing versus positive goal framing is 2.84 
(Fisher's exact test $p<0.001$ ). For the comparison between $500 \mathrm{~g}$ and $3400 \mathrm{~g}$ $\mathrm{CO}_{2}$ amounts, the odds ratio that the difference will be interpreted as "much" is $22.89(p<0.001)$.

Table 1

Results of the OL estimation for perception of difference (final model)

\begin{tabular}{lcccc}
\hline Coefficient definition & Value & Std err & t-Test & $p$-Value \\
\hline Negative goal framing & 1.59 & 0.229 & 6.97 & $<0.001$ \\
Large $\mathrm{CO}_{2}$ emissions (choice set 2) & 0.62 & 0.217 & 2.84 & $<0.001$ \\
Threshold 1 (from "about the same" to "slightly & -1.35 & 0.206 & -6.53 & $<0.001$ \\
different") & & & & \\
Threshold 2 (from "slightly" to "much different") & 0.538 & 0.179 & 3 & $<0.001$ \\
Number of estimated parameters & 4 & & & \\
Number of observations & 388 & & & \\
Null log-likelihood & -426.3 & & & \\
Final log-likelihood & -316.5 & & & \\
Likelihood ratio test & 219.5 & & & \\
$\rho^{2}$ & 0.258 & & & \\
Adjusted $\rho 2$ & 0.248 & & & \\
\hline
\end{tabular}

\section{Discussion}

$\mathrm{CO}_{2}$ emissions are a relatively new concept for many travellers. Even among those who have a high level of climate change awareness and are concerned about travel-related emissions, perceiving or valuing the differences between alternatives is likely to be a challenging task. Climate change can be considered a social dilemma, rather than an individual problem, and is largely framed as a normative goal. This point suggests that people may not have as strong a tendency to personally avoid environmental losses associated with transport alternatives (Lindenberg and Steg, 2007), thus lowering the potential effectiveness of negative valence framing as their desire to avoid it may not be as strong as those for personal impacts (e.g. hedonic or gain goals). In addition, most individuals have little or no experience with $\mathrm{CO}_{2}$ emissions. Research suggests that such information may therefore not be useful as people have difficulty interpreting the information or perceive the differences between $\mathrm{CO}_{2}$ amounts. As individuals do not consider transportrelated $\mathrm{CO}_{2}$ as a personal gain or loss, they have little experience dealing with $\mathrm{CO}_{2}$ emissions information, and the dominant format of mass is not well understood. It may for these reasons be difficult for individuals to attend to a difference between $\mathrm{CO}_{2}$ amounts. 
If individuals do not consider $\mathrm{CO}_{2}$ emissions as a loss and have difficulties in the interpretation of $\mathrm{CO}_{2}$ information, then why should valence framing be of relevance to the design of such information? Our argument in favour of considering framing of $\mathrm{CO}_{2}$ information (supported by our findings) centres on the persuasive effectiveness of negative framing reported in the literature and further substantiated in the present study. We argue that the alternative explanation suggested by Meyerowitz and Chaiken (1987) and further developed by Levine et al. (1998) account for our results. The negativity bias in processing information enhanced the impact of transport-related $\mathrm{CO}_{2}$ information presented in negative terms on perception and judgment than equivalent $\mathrm{CO}_{2}$ amounts presented in positive terms, highlighting and enhancing the perceived differences between alternative transport choices.

The findings reported here suggest that negative valence framing of $\mathrm{CO}_{2}$ emission amounts is an effective means of increasing the perceived difference and superior to positive framing of the same information. Although the $\mathrm{CO}_{2}$ amounts do not have a direct private cost, framing was still found to work. Considering the effectiveness of negative framing in other fields, and the specific findings reported here, it can be suggested that valence framing information on transport-related $\mathrm{CO}_{2}$ emissions can be applied to situations where $\mathrm{CO}_{2}$ information is being presented to better highlight desirable choices. This includes transport-related tools and measures, such as on-line journey planners, Personal Travel Plans (PTPs), or $\mathrm{CO}_{2}$ tax bands on cars. Future research should test our findings in experiments investigating mode choice or car purchases to test whether applying a negative framing of travel information to highlight the less (socially or environmentally) desirable choices has a positive effect on the likelihood of an individual perceiving an augmented difference between alternatives, and thus making more sustainable choices.

Comparing the responses from the two sets of $\mathrm{CO}_{2}$ amounts, it looks like negative goal framing exhibited in participants' responses was accentuated by an increase in scale. This suggests that larger comparisons may be more effective at increasing the perceived difference than smaller ones. As the mode choices will limit what could be shown on a trip-by-trip basis, potentially accumulated amounts like yearly outputs could be more effective. However, this was not an anticipated result and remains a question for future studies.

Although the different impacts of the negative goal framing due to the scale were not anticipated, several interpretations are plausible. The first is that the ratio between the two amounts within each comparison set is different with the first being 1:3.8 (132:500g) and the other 1:6.8 (500:3400g). However, the odds ratio is nearly ten times larger. The second possible explanation is the absolute difference between the amounts with the first comparison set differing by $368 \mathrm{~g}(500 \mathrm{~g}-132 \mathrm{~g})$, whereas the second differs by $2900 \mathrm{~g}(3400 \mathrm{~g}$ $500 \mathrm{~g})$. Here, the amounts nearly differ by a scale of $1: 7.8$ (368:2900) which is closer to the observed difference. The third suggested explanation is related to the unit. Would the interpretation have varied if kilograms were used rather than grams? Negative goal framing would still likely have an effect, but the magnitude of that effect may vary depending on if the differences were expressed as $0.368 \mathrm{~kg}$ and $2.90 \mathrm{~kg}$ rather than $368 \mathrm{~g}$ and $2900 \mathrm{~g}$. In that situation, perhaps the first comparison set would not have seemed different. 
Further, the implicit specification that $\mathrm{CO}_{2}$ emissions contribute to climate change and that this is to be avoided was not made. The participants were assumed to know this connection and that by highlighting a larger $\mathrm{CO}_{2}$ emissions amount as being worse and a smaller amount being better the normative goal framing would apply. Therefore, these results may not be replicated in situations where climate change awareness is low or where knowledge of $\mathrm{CO}_{2}$ emissions contributing to climate change is not common knowledge.

More consideration should be given to how travel information is presented. Beyond valence framing there is a potential for a range of contextual effects to enhance the effect of information, whether the framing is hedonic, gain, or normative. The potential application of such findings would be for governments (and other providers of travel information) to enable, highlight more sustainable travel choices. Recently there has been an increasing interest in the influence that psychological and social factors have on travellers' behaviour. So-called soft transport policies were implemented in the UK under the name Smarter Choices (see, e.g., Cairns et al., 2004). Somewhat inspired by social psychology (although not applying systematic frameworks in the design and evaluation of measures), Smarter Choices is a wide range of rather diverse measures including persuasive and information elements. In a similar vein, Thaler and Sunstein (2008) and other behavioural economists suggest that through a "choice architecture", and the incorporation of so-called "nudges" into the choice environment, policy makers can devise interventions that help people make better decisions. Incorporating valence framing and other factors having contextual effects in the design of information to influence travel choices could be seen as relevant techniques that are much in line with the rationale of both the Smarter Choices and the nudge agendas. This calls for further investigation of contextual effects on individual perceptions and choices of travel alternatives, and for the development of tools to design and evaluate effective information formats.

\section{Acknowledgements}

This research was funded in part by the European Commission's Framework Seven project "Carbon Aware Travel Choices" (CATCH; www.carbonaware.eu). Findings reported in this paper were presented at the $9^{\text {th }}$ Biennial Conference on Environmental Psychology, September 2011, at Eindhoven, The Netherlands.

The authors wish to thank the editors of this special issue for comments on an earlier draft of this paper. 


\section{References}

Armstrong, K., Schwartz, J.S. Fitzgerald, G., Putt, M. and Ubel, P.A. (2002). Effect of framing as gain versus loss on understanding and hypothetical treatment choices: Survival and mortality curves. Medical Decision Making 22(1), 76-83.

Avineri, E. (2006). The effect of reference point on stochastic network equilibrium. Transportation Science 40(4), 409-420.

Avineri, E. (2012). On the use and potential of behavioural economics from the perspective of transport and climate change. Manuscript submitted for publication.

Avineri, E. and Prashker, J.N. (2004). Violations of expected utility theory in route-choice stated preferences: Certainty effect and inflation of small probabilities. Transportation Research Record: Journal of the Transportation Research Board 1894, 222-229.

Ben-Elia, E., and Ettema, D. (2009). Carrots versus sticks: Rewarding commuters for avoiding the rush-hour - a study of willingness to participate. Transport Policy 16, 58-76.

Bierlaire, M. (2003). BIOGEME: A free package for the estimation of discrete choice models. In: Proceedings of the $3^{\text {rd }}$ Swiss Transportation Research Conference, Ascona, Switzerland.

Bierlaire, M. (2008). Estimation of discrete choice models with BIOGEME 1.6. Transport and Mobility Laboratory, EPFL, Lausanne, Switzerland.

Cairns, S., Sloman, L., Newson, C., Anable, J., Kirkbride, A. and Goodwin, P. (2004).

Smarter choices - changing the way we travel. [online]. London: Department for Transport. Available from: http://eprints.ucl.ac.uk/1224/ [Accessed 27, Oct., 2011].

Coulter, A., Clegg, S., Lyons, G., Chatterton, T. and Musselwhite, C.B.A. (2007). Exploring public attitudes to personal carbon dioxide emission information. London: Department for Transport.

Eurobarometer. (2009) Special Eurobarometer 313: European's Attitudes Towards Climate Change. Eurobarometer. Available at: http://ec.europa.eu/public opinion/archives/ebs/ebs 313 en.pdf. Accessed Dec., 2011.

Fagley, N.S and Miller, P.M (1997). Framing effects and arenas of choice: Your money or your life. Organizational Behavior and Human Decision Processes 71, 355-373.

Gaker, D., Vautin, D., Vij, A., and Walker, J.L. (2011). The power and value of green in promoting sustainable transport behavior. Environmental Research Letters 6, 034010.

Gaker, D., Zheng, Y. and Walker, J. (2010). Experimental economics in transportation. Transportation Research Record: Journal of the Transportation Research Board 2156, 47-55.

Gonzales, M.H., Aronson, E. and Costanzo, M.A. (1988). Using social cognition and persuasion to promote energy conservation: a quasi-experiment. Journal of Applied Social Psychology 18(12), 1049-1066.

Hallahan, K. (1999). Seven models of framing: Implications for Public relations. Journal of Public Relations Research 11(3), 205-242.

Kahneman, D. and Tversky, A. (1979). Prospect theory: An analysis of decision under risk. Econometrica 47(2), 263-291.

Kühberger, A. (1998). The influence of framing on risky decisions: A meta-analysis. Organizational Behavior and Human Decision Processes 75(1), 23-55.

Levin, I.P., Schneider, S.L., and Gaeth, G.J. (1998). All frames are not created equal: A typology and critical analysis of framing effects. Organizational Behavior and Human Decision Processes 76(2), 149-188.

Lindenberg, S. and Steg, L. (2007) Normative, Gain and Hedonic Goal Frames Guiding Environmental Behavior. Journal of Social Issues, 63, 117-137.

McFadden, D. (1999). Rationality for economists. Journal of Risk and Uncertainty 19(1-3), 73-106. 
Meyerowitz, B.E., and Chaiken, S. (1987). The effect of message framing on breast selfexamination attitudes, intentions, and behavior. Journal of Personality and Social Psychology 52, 500-510.

Milinski, M., Sommerfeld, R.D., Krambeck, H., Reed, F.A., and Marotzke, J. (2008) The collective-risk social dilemma and the prevention of simulated dangerous climate change. Proceedings of the National Academy of Sciences 105, 2291-2294.

Rose, G. and Ampt, E. (2001). Travel blending: An Australian travel awareness initiative. Transportation Research Part D: Transport and Environment 6(2), 95-110.

Rose, J.M. and Masiero, L. (2010). A Comparison of the Impacts of Aspects of Prospect Theory on WTP/WTA estimated in preference and WTP/WTA Space. European Journal of Transport and Infrastructure Research 10, 330-346.

Simon, H.A. (1956). Rational choice and the structure of the environment. Psychological Review 63, 129-138.

Taniguchi, A., Hara, F., Takano, S., Kagaya, S. and Fujii, S. (2003). Psychological and behavioral effects of travel feedback program for travel behavior modification. Transportation Research Record: Journal of the Transportation Research Board 1839, 182-190.

Thaler, R.H. and Sunstein, C.R. (2008). Nudge: Improving Decisions about Health, Wealth and Happiness. New Haven, CT: Yale University Press.

Tversky, A. and Kahneman, D. (1991). Loss aversion in riskless choice: A referencedependent model. The Quarterly Journal of Economics 106(4), 1039-1061.

van de Kaa, E.J. (2010). Prospect theory and choice behaviour strategies, Review and synthesis from social sciences. European Journal of Transport and Infrastructure Research 10(4), 347-367.

Waygood, E.O.D. and Avineri, E. (2011) Does "500g of $\mathrm{CO}_{2}$ for a five mile trip" mean anything? Towards more effective presentation of $\mathrm{CO}_{2}$ information. Proceedings of the Transportation Research Board 90th Annual Meeting, Washington, D.C., January 23-27.

Whitmarsh, L. (2009) Behavioural responses to climate change: Asymmetry of intentions and impacts. Journal of Environmental Psychology 29, 13-23. 